\title{
Biomedical Applications of Photochemistry
}

\author{
Barbara Pui Chan, Ph.D.
}

Photochemistry is the study of photochemical reactions between light and molecules. Recently, there have been increasing interests in using photochemical reactions in the fields of biomaterials and tissue engineering. This work revisits the components and mechanisms of photochemistry and reviews biomedical applications of photochemistry in various disciplines, including oncology, molecular biology, and biosurgery, with particular emphasis on tissue engineering. Finally, potential toxicities and research opportunities in this field are discussed.

\section{Introduction}

$\mathbf{P}$ HOTOCHEMISTRY IS THE STUDy of photochemical reactions between light and molecules. Photochemical reactions can occur in natural processes such as photosynthesis of plants and in pathological processes such as photoaging of skin. Biomedical applications of photochemistry have been established in the last few decades in various disciplines, including oncology, molecular biology, and biosurgery. Recently, application of photochemistry in biomaterials and tissue engineering has started to gain increasing attention. Sharing similar basic mechanisms of photochemistry, these applications do differ in many aspects, including target molecules, molecular actions, light source, and optical window. In this review, the author aims to revisit the basic components and mechanisms of photochemistry, review biomedical applications in various disciplines with particular emphasis on tissue engineering, and discuss the challenges and research opportunities. Terminology used in this work is defined in Appendix I.

\section{Photochemistry}

Photochemical reactions are chemical reactions produced when photons are absorbed by either the target molecules or a third party, which may serve as the sensitizer/initiator/ crosslinker of the reactions. After absorbing the photons, the target molecules or the third-party molecules are elevated to higher energy levels. When these molecules fall into lower energy levels, the energy may pass to generate some highenergy species, which are reactive to surrounding molecules, including the target molecules. ${ }^{1}$

\section{Components}

Photochemical reactions require at least two components: the light source, which provides the photons, and the target molecules, which are able to react with the high-energy species produced by the system. Sometimes a third component, photosensitizer, photoinitiator, or photocrosslinker, may also present to mediate the photochemical reactions.

Light source. Electromagnetic radiation is a form of energy exhibiting both wave and particle properties. The whole electromagnetic spectrum consists of waves of different wavelengths covering from very short gamma rays to very long radio waves. Radiations at the central part of the light spectrum including ultraviolet (UV) light at $200-400 \mathrm{~nm}$, visible light at $400-760 \mathrm{~nm}$, and near infrared (NIR) light at $760-1000 \mathrm{~nm}$ are the commonly used energy source for photochemical reactions in various disciplines (Fig. 1). The electromagnetic wave consists of discrete packets of energy called photons, which can be emitted and absorbed, and therefore are transporters of energy. The energy of each photon is inversely proportional to the wavelength of the light. As a result, a photon of the UV radiation at $300 \mathrm{~nm}$ has twice the energy of a photon of the visible radiation at $600 \mathrm{~nm}$. It is generally true that photons that have higher energy can cause different types of photochemical reactions. ${ }^{1}$ There are two wavelength-specific considerations while choosing the light source. First, different wavelengths penetrate to different depths into a target medium, with longer wavelengths reaching deeper layers in general. For applications in chemistry, biochemistry, and molecular biology, penetration depth is usually not a limiting factor because the target molecules are usually in dilute solutions. However, for applications in oncology, biosurgery, and tissue engineering, the target molecules are dense matters-for example, biological tissues such as skin $^{2}$ and tendon, ${ }^{3}$ and biomaterials such as collagen gel. ${ }^{4}$ The maximal effective optical penetration, which means the maximum depth that photons can reach into a light-interacting medium, that is, the tissue or biomaterial of interests, must be determined before photochemical crosslinking is used. Readers are directed to 


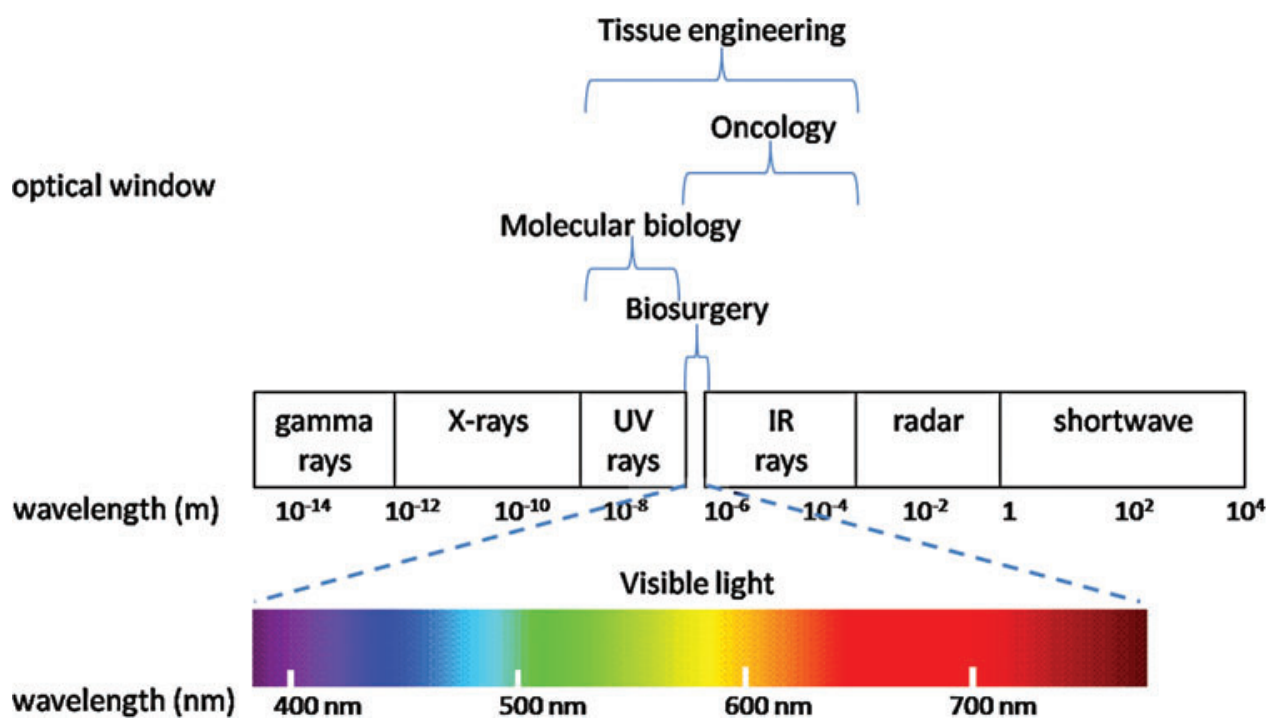

FIG. 1. Electromagnetic spectrum and optical windows in different disciplines. Color images available online at www.liebertonline .com/ten.

\section{optical window}

very low. Upon absorption of photons, a molecule is said to be in an excited state that contains higher energy than the ground-state molecule (Fig. 2). The excited molecules undergo different chemical and physical processes, including emission of light in terms of fluorescence and phosphorescence, formation of photoproducts, and generation of heat. ${ }^{1}$ In addition, the target molecules should also have the right chemistry to react with the reactive species or photoproducts generated upon photon absorption. Moreover, the presence of interfering molecules would affect the efficiency of photochemical reactions. For example, the presence of melanin in melanocytes and hemoglobin in capillaries ${ }^{8}$ significantly affects the interactions between light and collagen, which is the main target molecule in skin tissues.

Photosensitizer. When target molecules do not absorb light at certain wavelengths, or cannot be activated to produce appropriate photochemical reactions directly by light (e.g., nonpigmented collagen in human tissue does not readily absorb visible light), photosensitizers, which are usually fluorophores, that are able to absorb light at a particular wavelength, will be used to bind or stain the target molecules so as to mediate the light absorption and the subsequent photochemical reactions. Different generations of photosensitizers have been developed for PDT. ${ }^{9}$ These photosensitizers are shared by other disciplines. Different photosensitizers have specific optical properties such as absorption, emission, and fluorescence across the electromagnetic spectrum. It is important to match these characteristics with the respective wavelength used in the light source so as to assure maximal absorption. Light source with spectral wavelength matching the absorption maxima of the photosensitizer is usually selected. Another consideration for selecting photosensitizers is their quantum yield, which defines the yield of photoproducts, which are directly associated with the extent of photochemical reactions such as crosslinking, when the same amount of photosensitizer absorbs photons. ${ }^{10}$ As a result, photosensitizers with high quantum yield such as rose Bengal and porphyrins are excellent candidates for photochemical reactions. ${ }^{11}$ Photosensitizers do not necessarily need to have the right chemistry to react with or bind to the target molecules, but 


\section{$\mathbf{S}_{\mathbf{x}}=$ Singlet states}

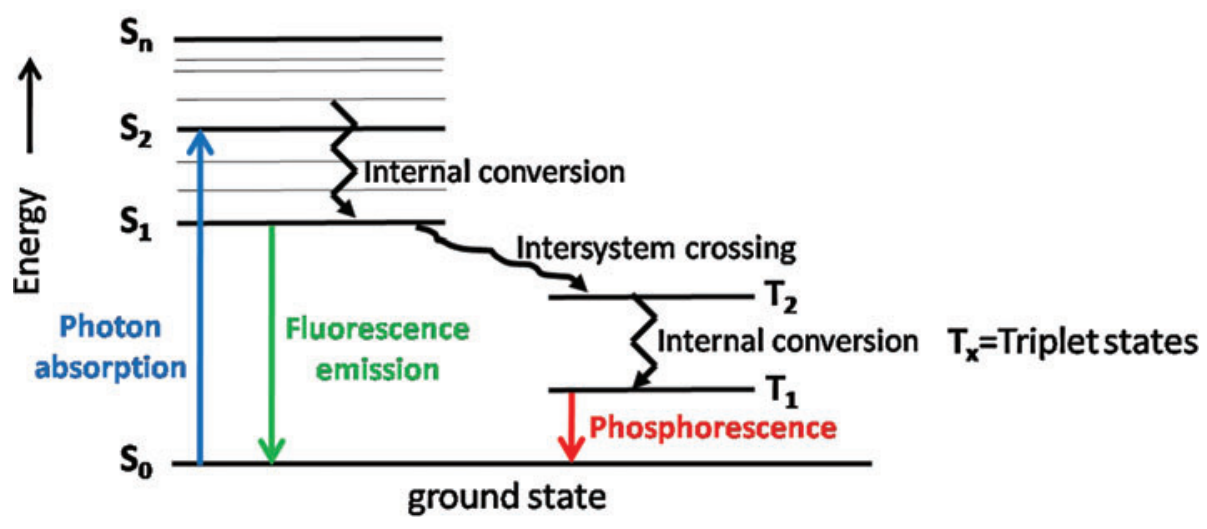

FIG. 2. Jablonski diagram. Color images available online at www.liebertonline .com/ten.

there should be a mechanism for the photosensitizers to stay in proximity to the target molecules. This is because photochemical reactions also occur through indirect mechanisms in addition to the direct mechanism. This shall be described in the subsequent section.

\section{Mechanisms}

Photochemical reactions in different disciplines share similar mechanisms via two competing pathways, direct and indirect (Fig. 3). Readers are directed to elsewhere for detailed description of the mechanisms. ${ }^{12-14}$

Direct (type I) mechanism. In direct (type I) mechanism, the light-activated photosensitizer interacts directly with the surrounding target molecules to form covalent crosslinks. ${ }^{15}$ Specifically, the activated photosensitizer reacts with oxygen or other adjacent molecules, including themselves, by electron transfer or hydrogen abstraction to form free radicals, which may further react with molecular oxygen to form reactive oxygen species such as hydrogen peroxide and hydroxyl radicals. ${ }^{12,16-18}$ In type I mechanism, the activated photosensitizer may form free radicals that are reactive to the target molecules and therefore consume themselves in the reactions.

Indirect (type II) mechanism. The presence of oxygen is necessary for the indirect (type II) mechanism to occur. In brief, the light-activated photosensitizer transfers energy to ground-state oxygen, thereby producing reactive singlet oxygen molecules, which are higher-energy oxygen molecules oxidizing the surrounding molecules. ${ }^{15,19}$ Moreover, the site of photochemical reaction is largely determined by the localization of the photosensistizer. ${ }^{20}$ This is attributable to the short radius of action of singlet oxygen. ${ }^{21}$ This characteristic is important as spatial control of the photochemical reaction can be administered by controlling the localization of the photosensitizer. Further, in type II mechanism, the activated photosensitizer returns to its ground state after energy transfer to molecular oxygen, and therefore recycles itself for another round of reaction. 22

Evidence of covalent bond formation. Evidence of covalent bonding formation in photochemistry mainly comes from research in protein crosslinking. It has been suggested that some amino acid groups such as tryptophan, tyrosine, ${ }^{23}$ histidine, ${ }^{23,24}$ cysteine, and methionine ${ }^{23}$ are vulnerable to photochemical reactions ${ }^{15,25}$; however, it has also been proposed that the crosslinking in proteins is nonspecific and the actual crosslinking sites could not be accurately located. ${ }^{25}$ The covalent nature of the photochemical reactions has been suggested by the reduced motility of crosslinked soluble proteins such as fibrinogen ${ }^{16}$ and lens protein crystallins ${ }^{15}$ upon sodium dodecyl sulfate-polyacrylamide gel electrophoresis in the presence of light and photosensitizing reagents.

\section{Biomedical Applications}

This section reviews the biomedical applications of photochemistry in four disciplines-namely, oncology, molecular biology, biosurgery, and tissue engineering, with particular emphasis on the last.

Table 1 summarizes and compares various aspects of these disciplines such as history, applications, target molecules, molecular mechanism, light source, optical window, and key challenges.

\section{PDT in oncology}

PDT is a treatment modality using photosensitizer and light and the subsequent photochemical reactions to kill cancer cells. PDT has been developed as an alternative cancer treatment for more than 40 years $^{26}$ and is the most wellknown and established biomedical application of photochemistry. Readers are directed to reviews of PDT. ${ }^{12-14,27}$ Both type I (direct) and type II (indirect) photochemical pathways are involved in PDT, ${ }^{12-14}$ while the indirect pathway with the formation of singlet oxygen is dominant. ${ }^{28,29}$ Although the exact mechanism of cancer killing by PDT is not fully understood, direct cytotoxicity on cancer cells via necrosis and apoptosis and indirect vascular effects and immunomodulation have been suggested. Direct cytotoxicity is aided by incorporation or binding of photosensitizers to subcellular organelles such as plasma membrane, lysosomes, Golgi apparatus, rough endoplasmic reticulum, and mitochondria. ${ }^{13}$ Cell necrosis is manifested by cell swelling, bleb formation, and shedding of vesicles containing cytosolic enzymers, ${ }^{13}$ whereas apoptosis is mediated by cytochrome $c$ released from mitochondria and caspase ${ }^{30}$ upon localization 


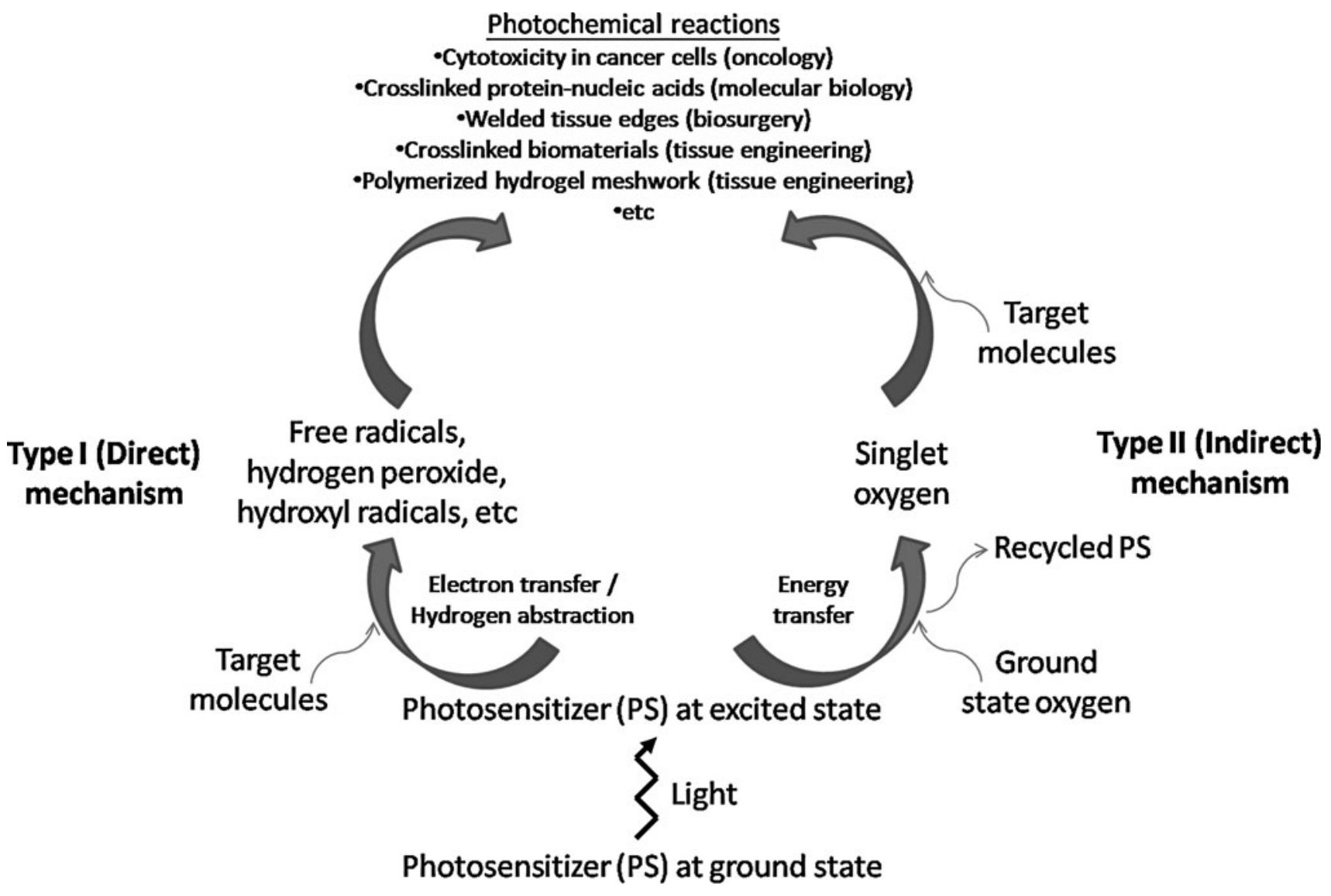

FIG. 3. Type I and type II mechanisms of photochemical reactions.

of photosensitizers to various subcellular organelles. Second, vascular effect refers to the hypoxia and anoxia of tumor tissue where the vasculature has been damaged due to effects of PDT on platelet activation and the subsequent thrombus formation and endothelium damage. ${ }^{31-33}$ Third, when the PDTdestroyed cancer cells are phagocytosed by macrophages and the cancer cell antigens are presented via antigen-presenting cells to the host immune system, enhanced immune response toward cancer cells may be resulted. ${ }^{34}$

Selective photosensitizer localization in target tissues and cells and the presence of sufficient concentration of molecular oxygen are important in assuring effective PDT. This is because of the short life span $(<40 \mathrm{~ns})$ and the short diffusion or action distance $(<0.02 \mu \mathrm{m})$ of singlet oxygen. ${ }^{21}$ Although the exact mechanism of preferential localization of photosensitizer in tumors is not entirely understood, low-density lipoprotein (LDL)-receptor-based uptake, hydrophobicity of the photosensitizer, lower $\mathrm{pH}$ in tumor, leaky vasculature, and poor tumor lymphatics have been suggested as the factors affecting the tumor specificity of photosensitizer. ${ }^{13}$

Laser light source is dominant in PDT. ${ }^{14}$ This is because of the high-energy coherent and monochromatic nature of light at a specific wavelength delivered by lasers and its easy and direct delivery through optic fibers into the target tissues in the human body. The right optical window between 600 and 800 or $1200 \mathrm{~nm}$ covering the visible and IR region has been identified in PDT. ${ }^{12,13}$ This is because, first, this window matches well with the absorption spectra of endogenous chromophores such as hemoglobin, melanin, and cytochromes; second, light at this spectral region is still energetic enough to produce singlet oxygen; and, third, this window has much better optical penetration depth into tissues. ${ }^{12}$

\section{Gene regulation study in molecular biology}

Photochemical crosslinking has been used as a powerful method for studying protein-nucleic acid interactions in the field of molecular biology. ${ }^{35}$ Protein-nucleic acid interactions in particular binding of transcription factors, which are usually proteins with specific target genes, are important in gene regulation. Rapid fixation or freezing of the specific binding between proteins and gene sequences at specific binding sites can be aided by photochemical crosslinking using light source dominated by UV, including inexpensive germicidal lamps ${ }^{36}$ and pulsed UV lasers. ${ }^{35}$ Frozen or snapshots of protein-nucleic acid complexes formed at different experimental conditions at different time points can be generated for subsequent analyses, including identification of specific proteins crosslinked to the complexes by immunochemical techniques, and identification and quantification of DNA sequences covalently attached to a given protein using hybridization techniques. ${ }^{35}$ By crosslinking the proteingene mixtures or cell nuclei at different time points, important kinetic and mechanistic studies of gene regulation, such as the TATA-binding protein adenovirus E4 promoter pair and the amyloid $\beta$-protein $(A \beta)$ neurotoxic oligomer pair, ${ }^{17}$ can be 
Table 1. Biomedical Applications of Photochemistry in Different Disciplines

\begin{tabular}{|c|c|c|c|c|}
\hline Disciplines & Oncology & Molecular biology & Biosurgery & Tissue engineering \\
\hline Application & $\begin{array}{l}\text { Photodynamic } \\
\text { therapy }\end{array}$ & $\begin{array}{l}\text { Photochemical } \\
\text { crosslinking }\end{array}$ & $\begin{array}{l}\text { Photochemical } \\
\text { tissue bonding }\end{array}$ & $\begin{array}{l}\text { Photochemical } \\
\text { crosslinking } \\
\text { Photopolymerization } \\
\text { Photodegradation }\end{array}$ \\
\hline History & $\sim 40$ years & $\sim 15$ years & $\sim 10$ years & $\sim 15$ years \\
\hline $\begin{array}{l}\text { Major } \\
\text { applications }\end{array}$ & Kill cancer cells & $\begin{array}{l}\text { Understand protein } \\
\text { nucleic acid } \\
\text { interactions }\end{array}$ & $\begin{array}{l}\text { Weld severed } \\
\text { tissues }\end{array}$ & $\begin{array}{l}\text { Stabilize scaffolds } \\
\text { Improve physicochemical } \\
\text { properties of materials } \\
\text { Modify material surface } \\
\text { chemistry and properties } \\
\text { Allow injectable or in situ } \\
\text { tissue engineering } \\
\text { Immobilize biomolecules } \\
\text { for controlled release } \\
\text { drug delivery } \\
\text { Generate patterns of } \\
\text { substrate, cell and } \\
\text { biomolecules }\end{array}$ \\
\hline Molecular actions & $\begin{array}{l}\text { Direct cytotoxicity } \\
\text { Indirect vascular } \\
\text { effects and } \\
\text { immunomodulation }\end{array}$ & $\begin{array}{l}\text { Rapid, mild, and } \\
\text { localized crosslinking } \\
\text { of transient and } \\
\text { specific protein- } \\
\text { nucleic acid } \\
\text { complexes }\end{array}$ & $\begin{array}{l}\text { Localized } \\
\text { crosslinking } \\
\text { of tightly } \\
\text { approximated } \\
\text { tissue edges }\end{array}$ & $\begin{array}{l}\text { Localized crosslinking of } \\
\text { photosensitizer-bound } \\
\text { extracellular matrix or } \\
\text { scaffolds or hydrogels } \\
\text { Simultaneously polymerize } \\
\text { monomers and entrap } \\
\text { biomolecules/cells with } \\
\text { remote controllability }\end{array}$ \\
\hline $\begin{array}{l}\text { Photochemical } \\
\text { pathway }\end{array}$ & $\begin{array}{l}\text { Types I and II while } \\
\text { type II dominates }\end{array}$ & $\begin{array}{l}\text { Types I and II while } \\
\text { type I dominates }\end{array}$ & Types I and II & Types I and II \\
\hline Target molecules & Cancer cells & $\begin{array}{l}\text { Transcription factors } \\
\text { and target genes }\end{array}$ & $\begin{array}{l}\text { Extracellular matrix } \\
\text { of tissues }\end{array}$ & $\begin{array}{l}\text { Extracellular matrix of } \\
\text { acellular tissues } \\
\text { Biomaterials }\end{array}$ \\
\hline Light source & Lasers dominate & UV lamps and lasers & Lasers dominate & Lasers dominate \\
\hline Optical window & $\begin{array}{l}\text { Visible and IR } \\
\text { region }\end{array}$ & UV region & Visible region & UV, visible, and IR region \\
\hline R\&D stage & Clinical trial & Basic research & $\begin{array}{l}\text { Proof of concepts } \\
\text { and preclinical }\end{array}$ & $\begin{array}{l}\text { Proof of concepts and } \\
\text { preclinical }\end{array}$ \\
\hline Main challenges & $\begin{array}{l}\text { Selective uptake of } \\
\text { photosensitizers by } \\
\text { tumor cells } \\
\text { Optical penetration } \\
\text { to deep tissues }\end{array}$ & $\begin{array}{l}\text { Correct identification } \\
\text { of specific protein } \\
\text { and nucleic acid } \\
\text { sequences }\end{array}$ & $\begin{array}{l}\text { Selective binding of } \\
\text { photosensitizers to } \\
\text { extracellular matrix } \\
\text { Optical penetration to } \\
\text { deep tissues } \\
\text { Minimize cytotoxicity } \\
\text { at tissue edges }\end{array}$ & $\begin{array}{l}\text { Understand the exact } \\
\text { mechanism } \\
\text { Minimize cytotoxicity in } \\
\text { cell-based systems } \\
\text { Minimize adverse effects } \\
\text { on bioactivities of } \\
\text { the immobilized } \\
\text { biomolecules }\end{array}$ \\
\hline
\end{tabular}

UV, ultraviolet; IR, infra red.

conducted. Three factors made the photochemical crosslinking useful in studying the protein-nucleic acid interactions. First, both amino acids and nucleic acids strongly absorb UV light, thus making them suitable target molecules for photochemical crosslinking. Second, photochemical crosslinking is a localized process where only molecules in proximity, such as those specifically bound with high affinity, can be crosslinked, thus minimizing the background produced by unbound or loosely bound molecules. Third, penetration depth is not a limiting factor in the process, as molecular complexes in diluted solutions, rather than thick tissue or dense matter with significant scattering, are crosslinked. The mechanism of UVmediated photochemical crosslinking in gene regulation studies is mainly type I (direct) mechanism. In brief, the molecules absorb photons, and by electron abstraction, they generate free radicals, which further react with adjacent reactive amino acids such as His, Met, and Tyr to form covalent complexes. ${ }^{17}$ Comparing with other crosslinking methods, photochemical crosslinking offers superior results as it results in high yield $(\sim 80 \%)$ of crosslinked products in a very short period $(<1 \mathrm{~s})$ without complicated modifications of proteins. ${ }^{17}$

\section{Photochemical tissue bonding in biosurgery}

Photochemical tissue bonding (PTB) presents another biomedical application of photochemistry and focuses on the surgical modalities of tissue repair, aiming to bond tissue edges or surfaces together. Surgical tissue repair is aided by either traditional suturing techniques or bioglues, but the former depends on the skills of the surgeons and is time 
consuming, whereas the latter triggers unfavorable immune reactions. Sutureless repair using laser welding techniques has been developed for decades, ${ }^{37}$ but the thermal nature of the welding procedure damages cell and tissue at the repair site, which may create complications. On the other hand, PTB has the advantage of being a nonthermal, rapid, and controlled technique. Physiological relevant temperature (below $40^{\circ} \mathrm{C}$ ) is involved in the bonding procedure. ${ }^{2}$ PTB is also a procedure inducing minimal cell and tissue damage, demonstrating that it is a safe procedure. Over the last decade, the feasibility and safety of using PTB in repairing multiple tissue systems in skin, ${ }^{2,38}$ cornea, ${ }^{39,40}$ meniscus, ${ }^{41,42}$ tendon, ${ }^{3}$ blood vessel, ${ }^{43}$ and nerve ${ }^{44,45}$ have been demonstrated. PTB shares the same mechanism with PDT because of the similarity in tissue-light interactions and the same photosensitizer systems used such as xanthenes $\mathrm{s}^{2,3,38-40,43-45}$ and naphthalimides, ${ }^{41,42,46}$ and similar light sources using visible lasers. Unlike PDT, extracellular matrix such as collagen, rather than cells, is the main target molecule for bonding in PTB, based on early studies demonstrating the photochemical crosslinking effect of collagen type I fibrils or other proteins. ${ }^{47,48}$ Although cells at tissue edges or surfaces are not the main targets for PTB, cell damage has been reported in the bonded tissues, including meniscus ${ }^{41}$ and skin. ${ }^{2}$ Such cell damage has been suggested to associate with the thermal toxicity of laser irradiation at high irradiances $(1.68$ and $\left.1.8 \mathrm{~W} / \mathrm{cm}^{2}\right)^{2,41}$ and the inherent photosensitizer toxicity. ${ }^{41}$ Similar to PDT, light and photosensitizer doses are important parameters determining the effectiveness of PTB. It is generally agreed that photosensitizer dosage $e^{2,3,39,40,42}$ and laser fluence rate $\left(\mathrm{J} / \mathrm{cm}^{2}\right)^{2,3,42}$ significantly affect the outcomes of PTB in terms of mechanical properties of tendon and menisci, ${ }^{3,42}$ adherence properties of skin grafts, ${ }^{2}$ and intraocular pressure of cornea. ${ }^{40}$ Similar to all light-tissue interaction processes, optical penetration is certainly a limiting factor in PTB because different tissues have different scattering, refraction, and absorption properties. As a result, measurement of effective optical penetration depth should be accompanied by all PTB studies in different tissue systems. For example, argon laser at $514 \mathrm{~nm}$ has an effective penetration depth of $\sim 350 \mu \mathrm{m}$ in $\operatorname{skin}^{49}$ and $\sim 680 \mu \mathrm{m}$ in tendon. ${ }^{3}$ This information is important to determine the maximal thickness of tissues that can be effectively bonded. For PTB to be effective, tightly approximately tissue edges with molecular contacts are necessary, as photochemical crosslinking is localized.

\section{Photochemical crosslinking and polymerization in tissue engineering}

There are increasing interests in using photochemical crosslinking as a biomaterial processing technology and photopolymerization as a biofabrication technology in tissue engineering.

Advantages over chemical and physical methods. Crosslinking methods, either chemical or physical, ${ }^{50,51}$ have been used to improve the properties of biomaterials, but they have significant limitations. ${ }^{52}$ Chemical means such as glutaraldehyde crosslinking is a widely used approach and is most efficient in producing the highest mechanical strength in scaffolds compared with other chemical reagents. ${ }^{53}$ How- ever, problems such as induction of cytotoxicity and calcification in host tissue due to incomplete removal of the toxic residues, aldehydes, and other metabolites are evident. ${ }^{50,54,55}$ This compromises the biocompatibility of the scaffolds. Other chemical crosslinking reagents such as carbodiimide and its derivatives may alleviate the potential biocompatibility drawback, but the crosslinking process is very time consuming. ${ }^{56,57}$ Finally, it is difficult to exert spatiotemporal control over chemical crosslinking process, as the crosslinking process immediately starts as the target molecules are mixed with the crosslinking reagent in solutions.

Physical crosslinking can be achieved by heat ${ }^{51}$ and dehydrothermal treatment, ${ }^{58}$ and gamma-irradiation. ${ }^{56}$ In general, physical crosslinking usually uses either very highenergy radiation such as UV and gamma, or high temperature and pressure to melt or solder the materials together. Most, if not all, materials with inferior physical properties have absorption of these high-energy sources and can react with these means. In other words, as long as the temperature can melt these materials, they can be physically bonded together. However, these methods usually have to denature or destroy the materials first before crosslinking together, thus compromising the stability of biomaterials via thermal degradation $^{51,56}$ and protein denaturation. ${ }^{57,58}$ These methods are also very time consuming, usually requiring hours to days. 57,58

Photochemical crosslinking has been used to modify the properties of biomaterials in 2000s. Comparing with chemical and physical crosslinking, photochemical crosslinking possesses several important advantages. First, it is a controllable process with many controllable parameters such as laser energy, power density, fluence, and photosensitizer concentration. Second, photochemical crosslinking has certain selectivity in where to crosslink. In other words, spatial control over the crosslinking process can be exerted. Selectivity is achieved as photochemical crosslinking only occurs when both light and photosensitizer present and when the target molecules are at the proximity of the photosensitizer and light. ${ }^{20}$ Third, temporal control can be exerted over the process. Reaction can be triggered by, first, combining the photosensitizer with the target molecules in darkness and then switching on the light source, or reaction can be easily terminated by turning off the light source at any time. Fourth, photochemical crosslinking is a rapid and efficient process. The duration of photochemical crosslinking usually ranged from seconds to minutes. The efficiency of photochemical crosslinking is usually high with the high yield of crosslinking up to $80 \% .{ }^{17}$ This is partially achieved by selecting photosensitizers with high quantum yield.,11 Finally, photochemical crosslinking has little toxicities comparing with other crosslinking methods.

Biomaterials suitable for photochemical crosslinking and polymerization. Not all biomaterials are able to be photochemically crosslinked. Readers are directed to the review on different types of materials able to be photochemically crosslinked. ${ }^{18}$ Hydrogels and natural biomaterials, including proteins, glycoprotein, and carbohydrates, need modifications on their physicochemical properties via crosslinking because these materials usually have poorer physicochemical properties comparing with other biomaterials such as ceramics and synthetic polymers, although with better biocompatibility. 
Nevertheless, whether a material can be photochemically crosslinked also depends on factors such as its chemistry and optical properties. First, materials suitable for photochemical crosslinking need to have the right functional group for the photosensitizer to bind and interact. For example, photochemical crosslinking of collagen-rich tissues such as skin ${ }^{2}$ and tendon ${ }^{3}$ and collagen gels ${ }^{4,59}$ using rose Bengal as the photosensitizer is easy, but crosslinking of proteoglycan-rich tissue such as cartilage and meniscus is difficult because rose Bengal does not readily bind to the negatively charged proteoglycans (unpublished data). Second, the optical properties of the material should not adversely interfere with the absorption properties of the photosensitizer. For example, tendon tissue with shiny white appearance reflects a lot of light and therefore results in lower effective optical penetration depth $\left(\delta_{\text {eff }}\right)(680 \mu \mathrm{m})^{3}$ compared with the nearly transparent collagen gel where the $\delta_{\text {eff }}$ has been found to be $\sim 30 \mathrm{~mm}^{4}$ The optical properties of the material itself, collagen gel in this case, would greatly affect $\delta_{\text {eff }}$ in the presence of the lightabsorbing photosensitizers, rose Bengal in this case, as $\delta_{\text {eff }}$ reduces exponentially as the concentration of the photosensitizer increases. ${ }^{4}$

Major applications in tissue engineering. Among different disciplines, tissue engineering finds most broad and diversified applications for photochemistry. This section reviews the major applications of photochemistry in tissue engineering.

Stabilization of acellular scaffolds: Photochemical crosslinking has been used to stabilize acellular tissues or prostheses particularly for cardiovascular tissues. ${ }^{24,60}$ It is demonstrated that the main target molecules for photochemical crosslinking in the acellular tissues is collagen. ${ }^{23,61}$ Xenogenic and allogenic pericardium, small-diameter blood vessels, ${ }^{62}$ and heart valves ${ }^{24,63}$ have been modified by photochemical crosslinking with retained texture, pliability, and shrinkage temperature comparing with the untreated acellular tissues but with improved chemical, enzymatic, and in vivo stability. ${ }^{62,64}$ Comparing with chemically processed acellular tissues, photochemically crosslinked tissues are noncalcifying, ${ }^{62,63}$ nonimmunogenic, biocompatible, ${ }^{65}$ and noncytotoxic. ${ }^{66}$

Improvement of the physicochemical properties of biomaterials: Photochemical crosslinking has been used to modify and improve the physicochemical properties of biomaterials, in particular, hydrogel and natural biomaterials such as collagen, ${ }^{4,59}$ fibrinogen, ${ }^{67}$ and alginate ${ }^{68}$ Mechanical properties, including tensile ${ }^{3,4,69}$ and compression ${ }^{4}$ properties, have been significantly improved such that the processed materials can be used for load-bearing applications. In vitro thermal stability ${ }^{59}$ and in vivo tissue stability ${ }^{4}$ of the processed biomaterials have also been improved. Many hydrogel-based and natural biomaterials swell rapidly upon hydration. This not only speeds up biodegradation but also leads to rapid loss in mechanical integrity. Photochemical crosslinking significantly improved the swelling properties of hydrogels made of collagen, ${ }^{4,59}$ alginate, $^{68}$ and dextran. ${ }^{70}$

Surface modification for improvement of biocompatibility: Surface modification of biomaterial surface via photochemical reactions has been used for many years. ${ }^{71-73}$ One important surface property improved by photochemical modification is the hematocompatibility of thrombogenic materials such as titanium, polyurethane, and collagen. UVbased photochemical process has been used to couple fibronectin to titanium surface ${ }^{74}$ and heparin to polyurethane, ${ }^{75}$ whereas visible light has been used to crosslink polyurethane film $^{76}$ and collagen hydrogel, ${ }^{4}$ all to reduce thrombogenicity with reduced platelet adhesion and fibrin mesh formation. The improved hematocompatibility enables the cardiovascular applications of these processed material. Immobilization of bioactive factors to the surfaces of certain biomaterials via photochemical reactions is also commonly used to improve the biocompatibility of materials. For examples, epidermal growth factors (EGFs) have been immobilized to chitosan surfaces, ${ }^{77}$ chitosan, and then gelatin to poly (lactide-co-glycolide) acid $^{78}$ via UV-mediated process, both to improve fibroblast adhesion and proliferation on these biomaterials, thus making these materials more cytocompatible.

Injectable or in situ tissue engineering: Photochemical crosslinking has been used to polymerize hydrogels made of both synthetic and natural biomaterials such as polyethylene glycol (PEG) ${ }^{79}$ alginate, and hyaluronan.$^{80}$ Readers are directed to reviews ${ }^{18,81,82}$ on photopolymerization of hydrogel materials. The most important feature of photopolymerized hydrogel is the ability to undergo the sol-gel transition in situ, in other words, to apply as a liquid, initiate lightactivated polymerization, and then form the gel at the injury site. As a result, many biological molecules or living cells can be entrapped within the solid gel network, acting as a convenient drug or cell delivery device. The temporal controllability of photoactivated process can be achieved by shining light after, during or immediately before injection. This also enables homogenous distribution and easy delivery of cells or biomolecules in the material when it is at its liquid state. For example, photopolymerization of PEG diacrylate derivatives resulted in microspheres entrapping islets, which remained viable for prolonged periods and were glucose responsive. ${ }^{83}$ The mechanism of photopolymerization of hydrogels has been suggested to be radical chain polymerization, in which the rate of initiation depends on parameters such as photoinitiator concentration and light intensity, the rate of propagation or polymerization depends on the occupation rate of double bonds by the radicals formed, and the rate of termination depends on the amount of radicals formed. ${ }^{18}$ The mechanisms of the photopolymerized hydrogel in cell and drug delivery are easy to comprehend, as polymer chain networks are formed from single chains and therefore entrap the molecules or cells being delivered, while the rate of degradation of the polymerized material is based on hydrolysis and enzymatic breakdown. ${ }^{18}$ The advantage of photochemistry-based process over thermal process is the physiological relevant temperature $\left(33^{\circ} \mathrm{C}-46^{\circ} \mathrm{C}\right),{ }^{2,84}$ which retains the stability and bioactivity of the proteins during the encapsulation process. As a result, photochemically processed hydrogels and structures are most suitable for drug delivery and cell delivery applications. ${ }^{67,82,85}$ Natural biomaterial-based photopolymerization systems such as gelatin, hyaluronan, dextran, and chitosan usually need chemical modification to provide photocrosslinkable moieties. ${ }^{18} \mathrm{UV}$ seems to be the dominant light source to photopolymerize synthetic hydrogel systems, whereas visible light is commonly used for naturally occurring systems ${ }^{18}$ perhaps 
due to the well-known damaging effects of UV on biomolecules such as proteins and DNA. Multiphoton excitation at the NIR region (780-850 $\mathrm{nm}$ ) with femtosecond pulses, and the subsequent nonlinear absorption of photons at extremely high intensity has been found effective in photochemical crosslinking proteins such as fibrinogen, ConA, bovine serum albumin, fibronectin, and type I collagen in the presence of photosensitizers. ${ }^{85,86}$

Controlled release drug delivery: Many photopolymerizable hydrogels such as PEG methacrylate derivatives, polyvinyl alcohol derivatives, and dextran methacrylate are by default controlled release drug delivery systems ${ }^{18,81}$ because many parameters, including the light factors, the material factors, and the drug factors, can be controlled so as to achieve controlled release. Photochemical reactions add further spatial and temporal controllability in the release patterns and rates of the immobilized or loaded biomolecules or drugs to many drug delivery systems, which can selfassemble or polymerize from smaller units into gels or fibrous meshwork under conditions such as ionic and hydrophobic interactions, ${ }^{82}$ such as alginate, hyaluoronan, fibrinogen, ${ }^{87}$ and collagen. ${ }^{88}$ Taking collagen as an example, collagen extracted from natural sources is able to selfassemble into gels consisting of fibrous meshwork for more than two decades ${ }^{88}$ and has been used to deliver protein drugs ${ }^{89}$ and cells. ${ }^{90}$ However, the fibrous meshwork formed by such self-assembled process is still very open that the mesh size is around $300-400 \mathrm{~nm} .^{91,92}$ This loose meshwork is difficult to retain bioactive molecules or drugs, which are usually less than several nanometers in size, within the meshwork by providing diffusion barriers. ${ }^{91,92}$ Photochemical crosslinking using photosensitizer rose Bengal and green light has been used to modify the release properties of proteins, including bovine serum albumin and nerve growth factor, from collagen microspheres and slab gels. ${ }^{91,92}$ The mechanism of photochemical crosslinking in controlling the protein release rate in these collagen structures is not entirely known but has been suggested as a secondary retention mechanism that may involve multiple protein-matrix interactions, including, but are not limited to, electrostatic and hydrophobic interactions with the entrapped proteins. ${ }^{91,92}$

Generation of patterns for substrate, cell, and biomolecules: In photochemical reactions, spatial and temporal control can be exerted because the reaction only occurs when all necessary components, including the photosensitizer, the material, and the light source, are present simultaneously. This controllability in where and when the photochemical reaction occurs enables generation of patterns in the substrate material, the cells bind to the substrate or the biomolecules immobilized in the substrates. Poly(acrylic acid)/ polyacrylamide-based multilayer films has been irradiated with UV irradiation through a photo mask, resulting in micropatterns of the substrates and therefore patterned adhesion of MG63 and L929 cells. ${ }^{93}$ Cell patterns can also be generated by creating gradient patterns of bioactive molecules. UV irradiation has been used to photoimmobilize EGF at patterned locations via the phenyl azide functionality of the Sulfo-SANPAH, a heterobifunctional crosslinker, so as to create EGF gradient. ${ }^{94}$ Human keratinocytes have been found fivefold faster in migration on such patterned surface than on the control surfaces. ${ }^{94}$ Spatially resolved photolysis of an EGF-immobilized synthetic polypeptide resulted in patterned and gradients chemotactic and mitogenic signals, and therefore resulted in spatial patterning of fibroblasts. ${ }^{95}$

\section{Potential Toxicities and Remedies}

Whether there is any adverse effect on cells is an important question to ask if photochemical crosslinking is to be used in tissue engineering for future clinical application. Major potential toxicities of photochemical reactions are chemical, thermal, or photochemical in nature. First, chemical toxicity should come from the photosensitizer/photoinitiator/ photocrosslinker. However, pure chemical toxicity of the photosensitizer has not been studied at all. Nevertheless, the chemical toxicity is speculated to be low because many photosensitizers are vital dyes for cells. For example, rose Bengal has been used as a vital dye in the diagnosis of ophthalmological diseases for decades at concentrations up to $1 \%(\mathrm{w} /$ v). ${ }^{96}$ Moreover, the concentration of photosensitizer used in photochemical reaction is usually low due to their high quantum yield ${ }^{1}$ and therefore reduces the possibility of having chemical toxicity if any on cells. Second, thermal toxicity comes from the light source of the system, be it laser or LED, but the thermal toxicity should also be relatively low due to the theoretically nonthermal nature of photochemical reactions. Nevertheless, thermal damage is still possible if the irradiance of laser is high as demonstrated in previous studies. ${ }^{2,41}$ In the skin bonding study, maximal temperature at the skin surface increased rapidly to $>60^{\circ} \mathrm{C}$ at a higher irradiance $\left(1.68 \mathrm{~W} / \mathrm{cm}^{2}\right)$ but maintained $<40^{\circ} \mathrm{C}$ at lower irradiances $\left(\leq 1 \mathrm{~W} / \mathrm{cm}^{2}\right)$. This high irradiance was found to be correlated to the presence of cell necrosis and collagen denaturation in the photochemically bonded skin samples. ${ }^{2}$ Cooling via air or water is the most efficient means to prevent thermal damage, and a lower irradiance (well below $1 \mathrm{~W} /$ $\left.\mathrm{cm}^{2}\right)^{2}$ is always safer to use. Apart from thermal toxicity, radiation toxicity is also related to the light source. UV is able to denature proteins and damage DNA. As a result, UV-induced loss in bioactivity of proteins and mutagenicity of cells may be resulted. Third, photochemical toxicity is the major type of toxicities of photochemical reactions and is due to the presence of the reactive oxygen species produced. In PDT, the photochemical toxicity on cells acts as a mechanism of cell killing ${ }^{97}$ and is a wanted action, but in $\mathrm{PTB}^{2}$ and biomaterial processing, ${ }^{4,59}$ any photochemical toxicity on cells present at or near the site of crosslinking is unwanted. Some studies claimed no cytotoxicity, ${ }^{98,99}$ while others reported toxicity. ${ }^{2,18}$ Those studies claiming no toxicity need careful verification, as, theoretically, oxidative stress and damage should present due to the large amount of reactive oxygen species generated, but it is possible that some cells may survive the crosslinking process and further proliferate. Remedies to photochemical toxicity are to confine the photosensitizer within the materials being crosslinked rather than the surrounding cells. Supplementing the photosensitizer to the materials before adding cells is a possible way to reduce photochemical cytotoxicity, at least in 3T3 fibroblasts exposing to argon laser and rose Bengal (data not shown).

\section{Challenges and Opportunities}

This section discusses the key challenges faced by applying photochemistry in tissue engineering and various opportunities for future development in this field. 


\section{Difficulties on mechanistic studies in dense matter materials}

Investigating the detailed mechanisms of photochemical crosslinking is challenging. Direct evidence of covalent bond formation by methods such as Fourier transform infrared spectroscopy is lacking in biomaterials being processed because it is a challenging task to investigate detailed mechanisms of photochemical crosslinking in dense-matter materials compared with the simple chemistry system where samples are in extremely diluted concentrations. Extremely thin films of the crosslinked materials are necessary for Fourier transform infrared spectrum analysis. Moreover, identification of specific groups, in the material samples, reactive with the photosensitizer deserves further investigation. This can be realized by blocking a particular functional group or amino acid or chemically modifying a specific group or moiety with known mechanism and then evaluating the effects of the blocking or modification on the crosslinking efficiency. This shall yield important information on the significance of these functional groups on the crosslinking mechanism. For new comers in this field, to photochemically crosslink their materials, it is easier to start with some well-known photosensitizers with high quantum yield, ${ }^{1,11}$ and it is necessary to screen these photosensitizers for efficient binding and staining properties using the materials.

\section{Lack of in vivo evaluation studies}

Applications of photochemical reactions in tissue engineering have to be evaluated in animal models before translating them into clinical applications. However, most studies are proof-of-principle type and in vitro, and only a few in vivo evaluation studies could be found. First, histocompatibility, biostability, degradation rate, integration with host tissue, and potential toxicity of the photochemically modified materials with or without immobilized biomolecules or entrapped cells need to be investigated. A thorough evaluation study on photooxidized pericardial heart valves from bovine and porcine sources has demonstrated that the implants were noncytotoxic, nonhemolytic, and nonmutagenic 3 months postimplantation in rabbit models, while the low antibody level elicited was not due to the photooxidation process although new epitopes possibly collagen crosslinks might be generated. ${ }^{65}$ The same study also nicely demonstrated in sheep model that the functions of the photooxidized heart valves could last for at least 2 years with only a thin layer of host endothelial cells covering the implants. ${ }^{65}$ Second, optimized combinations of different parameters, including the light and bioactive factor dosimetry for in situ or injectable applications, need to be determined, as the efficacy obtained from in vitro study usually cannot be directly translated into animal studies. A first in vivo evaluation study on in situ delivery of mesenchymal stem cells (MSCs) via UV-based polymerization of poly(ethylene oxide) diacrylate hydrogel, in combination with hyaluronic acid and transforming growth factor beta 3, has demonstrated in vivo differentiation of the subcutaneously transplanted MSCs into chondrogenic lineages with proteoglycan and type II collagen production in athymic nude mice. ${ }^{100}$ This lays the foundation for future development of light-activated injectable tissue engineering. Third, the fate of the biomolecules and cells has to be tracked in vivo to understand the mechanism of actions. In this regard, noninvasive methods such as magnetic resonance imaging (MRI) in monitoring the implant changes should be explored. Although not in vivo, a photopolymerized poly(ethylene oxide) diacrylate hydrogel, seeded with bovine chondrocytes, has been imaged by MRI ex vivo. ${ }^{101}$ The increasing glycosaminoglycan contents in the constructs well correlated with the fixed charge density of the MRI signal, suggesting the usefulness of this in situ monitoring method. ${ }^{101}$

\section{Overcome limitations of existing biofabrication technology}

Electrospinning has been emerged as a useful fabrication technology for fiber-based porous scaffold for some time. ${ }^{102}$ Due to the excellent biocompatibility, natural biomaterials, including collagen and gelatin, ${ }^{103,104}$ become attractive candidates for electrospinning. Nevertheless, fibers made of these materials immediately dissolved upon addition of aqueous reagent. This limits the application of electrospun collagen or gelatin fibers for tissue engineering purposes. Some researchers even question whether electrospinning of collagen fiber is a rational and economical way to create fiber scaffold. ${ }^{105}$ There are indeed advantages to use naturally occurring materials such as collagen as scaffolds because of their excellent biocompatibility and negligible immunogenicity. ${ }^{106}$ However, modifications are needed because of their inferior physicochemical properties. Chemical crosslinking and physical crosslinking are uncontrolled, time-consuming processes. Photochemical crosslinking is able to exert spatiotemporal control over the crosslinking process and thus can initiate the crosslinking process by irradiating with the light source after the electrospinning process, while the photosensitizer can be supplemented to the polymer mixture before electrospinning. Preliminary data showed promising results of using photochemical crosslinking to solve the solubility problem with retained fiber morphology in electrospun collagen fibers. ${ }^{107}$

\section{Achieve better resolution with nano-features}

It is now generally accepted that cells can detect different topological cues surrounding them. ${ }^{108}$ As a result, creating features with patterns in the substrate material surrounding cells is one of the strategies to design scaffold with desired properties. Photochemical crosslinking has been used to create micropatterns in hydrogels ${ }^{109}$ and glass surface ${ }^{110}$ so as to study the effects of such features on cellular activities. It is recently demonstrated that cells respond differently to nano-sized features. ${ }^{110}$ Nanopatterns in hydrogel materials can be achieved by multiphoton-based photochemical crosslinking, as the high-intensity light has been focused to induce gelation of hydrogel materials at submicron focus where free-form fabrication in a liquid bath of the material is possible. Multiphoton microscopy-based fabrication of three-dimensional structures of protein-based materials with nano-features has been demonstrated. ${ }^{85,86}$ The advantage of using multiphoton-based photochemistry is the higher depth and lateral resolution of the nano-features being fabricated. Moreover, the use of IR laser as the light source further reduces cytotoxicity and offers the possibility to 
photochemically crosslink the materials in the presence of living cells.

\section{Control mechanical properties of substrate material}

It is generally agreed that cells are responsive to their mechanical microenvironment, which can be either the stiffness or compliance of the matrix that they are residing, or the stress and strain they are experiencing during loading. The work on inducing human MSCs to differentiate toward different lineages after seeding them on hydrogels with different elastic modulus ${ }^{111}$ has stimulated tremendous interests in controlling and modifying the substrate stiffness for regulation of stem cell fate, an important topic in tissue engineering. Photochemical reactions are known to modify properties of biomaterials, including mechanical properties such as stiffness and elasticity. Since photochemical reactions are highly controlled reactions compared with chemical and physical processes and the modification can be remotely controlled by triggering and pausing the processes via many processing parameters, ranging from light power to material concentration, substrates with a wide range of mechanical properties can be produced. A recent work on modifying and fine-tuning the elasticity of poly(ethylene glycol)-based hydrogel via addition of a photodegradable group further suggested the potential of using photochemical reactions to prepare substrates for directing differential cell activities. ${ }^{112}$ Photodegradable poly(ethylene glycol)-based hydrogels has been modified to give substrates of different elastic modulus simulating that of the soft tissues and has been found to activate differentiation of valvular interstitial cell into myofibroblasts. ${ }^{113,114}$

\section{Conclusions}

The fundamental components and mechanisms of photochemistry have been reviewed and its biomedical applications across various disciplines have been compared. Photochemistry finds the most broad and diversified applications in tissue engineering compared with other disciplines. Specifically, photochemical reactions can be used to stabilize acellular tissues and porous scaffolds, improve physicochemical properties of and modify the surface properties of many materials, polymerize or gelate simultaneously with biomolecules and cell entrapment so as to aid injectable tissue engineering and controlled release drug delivery, and generate patterns for substrate, cell, and biomolecules due to the spatial and temporal controllability of the process. Future directions in delineating the detailed mechanisms of photochemical crosslinking in processing biomaterials for scaffolding purposes, evaluating the photochemically modified materials and structures in animal models, improving existing biofabrication technologies such as electrospinning and micro-pattern generation, and controlling the substrate mechanical properties for regulating cell activities are warranted.

\section{Acknowledgments}

This work was supported by grants from AOSpine (AOSBRC-07-06); the Innovation and Technology Commission, the Hong Kong Government (GHP/050/06), and the
Strategic Research Themes of the University of Hong Kong on Biomedical Engineering and Bionanotechnology.

\section{Disclosure Statement}

No competing financial interests exist.

\section{References}

1. Kochevar, I.E. Principles of photobiology. In: Deleo, V.A., ed. Photosensitivity. New York: Igaku-Shoin Medical Publishers Inc., 1992, pp. 9-24.

2. Chan, B.P., Kochevar, I.E., and Redmond, R.W. Enhancement of porcine skin graft adherence using a light-activated process. J Surg Res 108, 77, 2002.

3. Chan, B.P., Amann, C., Yaroslavsky, A.N., Title, C., Smink, D., Zarins, B., Kochevar, I.E., and Redmond, R.W. Photochemical repair of Achilles tendon rupture in a rat model. J Surg Res 124, 274, 2005.

4. Chan, B.P., Hui, T.Y., Chan, O.C., So, K.F., Lu, W., Cheung, K.M., Salomatina, E., and Yaroslavsky, A. Photochemical cross-linking for collagen-based scaffolds: a study on optical properties, mechanical properties, stability, and hematocompatibility. Tissue Eng 13, 73, 2007.

5. Salomatina, E., Jiang, B., Novak, J., and Yaroslavsky, A.N. Optical properties of normal and cancerous human skin in the visible and near-infrared spectral range. J Biomed Opt 11, 064026, 2006.

6. Yaroslavsky, A.N., Schulze, P.C., Yaroslavsky, I.V., Schober, R., Ulrich, F., and Schwarzmaier, H.J. Optical properties of selected native and coagulated human brain tissues in vitro in the visible and near infrared spectral range. Phys Med Biol 47, 2059, 2002.

7. Barolet, D. Light-emitting diodes (LEDs) in dermatology. Semin Cutan Med Surg 27, 227, 2008.

8. Dawson, J.B., Barker, D.J., Ellis, D.J., Grassam, E., Cotterill, J.A., Fisher, G.W., and Feather, J.W. A theoretical and experimental study of light absorption and scattering by in vivo skin. Phys Med Biol 25, 695, 1980.

9. Juzeniene, A., Peng, Q., and Moan, J. Milestones in the development of photodynamic therapy and fluorescence diagnosis. Photochem Photobiol Sci 6, 1234, 2007.

10. Kochevar, I.E., and Redmond, R.W. Photosensitized production of singlet oxygen. Methods Enzymol 319, 20, 2000.

11. Juzeniene, A., Nielsen, K.P., and Moan, J. Biophysical aspects of photodynamic therapy. J Environ Pathol Toxicol Oncol 25, 7, 2006.

12. Plaetzer, K., Krammer, B., Berlanda, J., Berr, F., and Kiesslich, T. Photophysics and photochemistry of photodynamic therapy: fundamental aspects. Lasers Med Sci 24, 259, 2009.

13. Hsi, R.A., Rosenthal, D.I., and Glatstein, E. Photodynamic therapy in the treatment of cancer: current state of the art. Drugs 57, 725, 1999.

14. Pervaiz, S., and Olivo, M. Art and science of photodynamic therapy. Clin Exp Pharmacol Physiol 33, 551, 2006.

15. Balasubramanian, D., Du, X., and Zigler, J.S., Jr. The reaction of singlet oxygen with proteins, with special reference to crystallins. Photochem Photobiol 52, 761, 1990.

16. Webster, A., Britton, D., Apap-Bologna, A., and Kemp, G. A dye-photosensitized reaction that generates stable protein-protein crosslinks. Anal Biochem 179, 154, 1989.

17. Vollers, S.S., Teplow, D.B., and Bitan, G. Determination of Peptide oligomerization state using rapid photochemical crosslinking. Methods Mol Biol 299, 11, 2005. 
18. Ifkovits, J.L., and Burdick, J.A. Review: photopolymerizable and degradable biomaterials for tissue engineering applications. Tissue Eng 13, 2369, 2007.

19. Shen, H.R., Spikes, J.D., Kopeceková, P., and Kopecek, J. Photodynamic crosslinking of proteins. I. Model studies using histidine- and lysine-containing N-(2hydroxypropyl)methacrylamide copolymers. J Photochem Photobiol B 34, 203, 1996.

20. Avila, F., Matus, A., Fuentealba, D., Lissi, E., Friguet, B., and Silva, E. Autosensitized oxidation of glycated bovine lens proteins irradiated with UVA-visible light at low oxygen concentration. Photochem Photobiol Sci 7, 718, 2008.

21. Moan, J., and Berg, K. The photodegradation of porphyrins in cells can be used to estimate the lifetime of singlet oxygen. Photochem Photobiol 53, 549, 1991.

22. Vermeersch, G., Ronfard-Haret, J.C., Bazin, M., Carillet, V., Morliere, P., and Santus, R. Type I and type II photosensitization by the antibacterial drug nalidixic acid. A laser flash photolysis study. Photochem Photobiol 54, 661, 1991.

23. Ramshaw, J.A., Stephens, L.J., and Tulloch, P.A. Methylene blue sensitized photo-oxidation of collagen fibrils. Biochim Biophys Acta 1206, 225, 1994.

24. Adams, A.K., Talman, E.A., Campbell, L., Mcllroy, B.K., and Moore, M.A. Crosslink formation in porcine valves stabilized by dye-mediated photooxidation. J Biomed Mater Res 57, 582, 2001.

25. Hott, J.L., and Borkman, R.F. Analysis of photo-oxidized amino acids in tryptic peptides of calf lens gamma-II crystallin. Photochem Photobiol 56, 257, 1992.

26. Lipson, R.L., Baldes, E.J., and Olsen, A.M. Hematoporphyrin derivative: a new aid for endoscopic detection of malignant disease. J Thorac Cardiovasc Surg 42, 623, 1961.

27. Ortel, B., Shea, C.R., and Calzavara-Pinton, P. Molecular mechanisms of photodynamic therapy. Front Biosci 14, 4157, 2009.

28. Ito, T. Cellular and subcellular mechanisms of photodynamic action: the $1 \mathrm{O} 2$ hypothesis as a driving force in recent research. Photochem Photobiol 28, 493, 1978.

29. Weishaupt, K.R., Gomer, C.J., and Dougherty, T.J. Identification of singlet oxygen as the cytotoxic agent in photoinactivation of a murine tumor. Cancer Res 36(7 PT 1), 2326, 1976

30. Kessel, D., and Luo, Y. Mitochondrial photodamage and PDT-induced apoptosis. J Photochem Photobiol B 42, 89, 1998.

31. Fingar, V.H., Wieman, T.J., Karavolos, P.S., Doak, K.W., Ouellet, R., and van Lier, J.E. The effects of photodynamic therapy using differently substituted zinc phthalocyanines on vessel constriction, vessel leakage and tumor response. Photochem Photobiol 58, 251, 1993.

32. Gilissen, M.J., van de Merbel-de Wit, L.E., Star, W.M., Koster, J.F., and Sluiter, W. Effect of photodynamic therapy on the endothelium-dependent relaxation of isolated rat aortas. Cancer Res 53, 2548, 1993.

33. McMahon, K.S., Wieman, T.J., Moore, P.H., and Fingar, V.H. Effects of photodynamic therapy using mono-Laspartyl chlorin e6 on vessel constriction, vessel leakage, and tumor response. Cancer Res 54, 5374, 1994.

34. Korbelik, M. Induction of tumor immunity by photodynamic therapy. J Clin Laser Med Surg 14, 329, 1996.

35. Moss, T., Dimitrov, S.I., and Houde, D. UV-laser crosslinking of proteins to DNA. Methods 11, 225, 1997.

36. Buck, M., and Cannon, W. A simple procedure for visualising protein-nucleic acid complexes by photochemical crosslinking. Nucleic Acids Res 22, 1119, 1994.
37. Sauer, J.S., Hinshaw, J.R., and McGuire, K.P. The first sutureless, laser-welded, end-to-end bowel anastomosis. Lasers Surg Med 9, 70, 1989.

38. Kamegaya, Y., Farinelli, W.A., Vila Echague, A.V., Akita, H., Gallagher, J., Flotte, T.J., Anderson, R.R., Redmond, R.W., and Kochevar, I.E. Evaluation of photochemical tissue bonding for closure of skin incisions and excisions. Lasers Surg Med 37, 264, 2005.

39. Proano, C.E., Azar, D.T., Mocan, M.C., Redmond, R.W., and Kochevar, I.E. Photochemical keratodesmos as an adjunct to sutures for bonding penetrating keratoplasty corneal incisions. J Cataract Refract Surg 30, 2420, 2004a.

40. Proaño, C.E., Mulroy, L., Jones, E., Azar, D.T., Redmond, R.W., and Kochevar, I.E. Photochemical keratodesmos for bonding corneal incisions. Invest Ophthalmol Vis Sci 45, 2177, 2004b.

41. Pollo, F.E., Jackson, R.W., Kane, R.R., Chang, H.M., Zhang, J., Dieterichs, C.P., and Riedel, S. Sutureless avascular meniscal repair with a photoactive naphthalimide compound: a preliminary animal study. Arthroscopy 20, 824, 2004.

42. Skurla, C.P., Perera, A., Towe, C.T., Robertson, P.R., Healy, J.L., and Kane, R.R. Development of photochemical method for meniscal repair: a preliminary study. J Biomech 40, 220, 2007.

43. O'Neill, A.C., Winograd, J.M., Zeballos, J.L., Johnson, T.S., Randolph, M.A., Bujold, K.E., Kochevar, I.E., and Redmond, R.W. Microvascular anastomosis using a photochemical tissue bonding technique. Lasers Surg Med 39, 716, 2007.

44. Johnson, T.S., O'Neill, A.C., Motarjem, P.M., Amann, C., Nguyen, T., Randolph, M.A., Winograd, J.M., Kochevar, I.E., and Redmond, R.W. Photochemical tissue bonding: a promising technique for peripheral nerve repair. J Surg Res 143, 224, 2007.

45. O'Neill, A.C., Randolph, M.A., Bujold, K.E., Kochevar, I.E., Redmond, R.W., and Winograd, J.M. Photochemical sealing improves outcome following peripheral neurorrhaphy. J Surg Res 151, 33, 2009.

46. Zhang, J., Jeremy Woods, R., Brown, P.B., Mowery, R.A., Kane, R.R., Jackson, R.W., and Pollo, F. Photochemical tissue bonding using monomeric 4-amino-1,8-naphthalimides. J Biomed Opt 9, 1089, 2004.

47. Judy, M.M., Matthews, J.L., Boriack, R.L., Burlacu, A., Lewis, D.E., and Utecht, R.E. Photochemical crosslinking of proteins with visible light absorbing 1,8-naphthalimides. SPIE Proc 1882, 221, 1993.

48. Judy, M.M., Fuh, L., Matthews, J.L., Lewis, D.E., and Utecht, R.E. Gel electrophoresis studies of photochemical crosslinking of type I collagen with brominated 1,8naphthalimide dyes and visible light. SPIE 2128, 506, 1994.

49. Douven, L.F., and Lucassen, G.W. Retrieval of optical properties of skin from measurement and modeling the diffuse reflectance. Proc SPIE 3914, 312, 2000.

50. Khor, E. Methods for the treatment of collagenous tissues for bioprostheses. Biomaterials 18, 95, 1997.

51. Itoh, S., Takakuda, K., Kawabata, S., Aso, Y., Kasai, K., Itoh, H., and Shinomiya, K. Evaluation of cross-linking procedures of collagen tubes used in peripheral nerve repair. Biomaterials 23, 4475, 2002.

52. Hennink, W.E., and van Nostrum, C.F. Novel crosslinking methods to design hydrogels. Adv Drug Deliv Rev 54, 13, 2002.

53. Charulatha, V., and Rajaram, A. Influence of different crosslinking treatments on the physical properties of collagen membranes. Biomaterials 24, 759, 2003. 
54. Simmons, D.M., and Kearney, J.N. Evaluation of collagen cross-linking techniques for the stabilization of tissue matrices. Biotechnol Appl Biochem 17, 23, 1993.

55. Lee, J.E., Park, J.C., Hwang, Y.S., Kim, J.K., Kim, J.G., and Sub, H. Characterization of UV-irradiated dense/porous collagen membranes: morphology, enzymatic degradation, and mechanical properties. Yonsei Med J 42, 172, 2001.

56. Pieper, J.S., Oosterhof, A., Dijkstra, P.J., Veerkamp, J.H., and van Kuppevelt, T.H. Preparation and characterization of porous crosslinked collagenous matrices containing bioavailable chondroitin sulphate. Biomaterials 20, 847, 1999.

57. Billiar, K., Murray, J., Laude, D., Abraham, G., and Bachrach, N. Effects of carbodiimide crosslinking conditions on the physical properties of laminated intestinal submucosa. J Biomed Mater Res 56, 101, 2001.

58. Weadock, K.S., Miller, E.J., Bellincampi, L.D., Zawadsky, J.P., and Dunn, M.G. Crosslinking of collagen fibers: comparison of ultraviolet irradiation and dehydrothermal treatment. J Biomed Mater Res 29, 1373, 1995.

59. Chan, B.P., and So, K.F. Photochemical crosslinking improves the physicochemical properties of collagen scaffolds. J Biomed Mater Res A 75, 689, 2005.

60. Schmidt, C.E., and Baier, J.M. Acellular vascular tissues: natural biomaterials for tissue repair and tissue engineering. Biomaterials 21, 2215, 2000.

61. Bernstein, P.H., and Mechanic, G.L. A natural histidinebased imminium cross-link in collagen and its location. J Biol Chem 255, 10414, 1980.

62. Moore, M.A., Bohachevsky, I.K., Cheung, D.T., Boyan, B.D., Chen, W.M., Bickers, R.R., and Mcllroy, B.K. Stabilization of pericardial tissue by dye-mediated photooxidation. J Biomed Mater Res 28, 611, 1994.

63. Moore, M.A., Phillips, R.E., Jr., McIlroy, B.K., Walley, V.M., and Hendry, P.J. Evaluation of porcine valves prepared by dye-mediated photooxidation. Ann Thorac Surg 66 (6 Suppl), S245, 1998.

64. Moore, M.A., Chen, W.M., Phillips, R.E., Bohachevsky, I.K., and McIlroy, B.K. Shrinkage temperature versus protein extraction as a measure of stabilization of photooxidized tissue. J Biomed Mater Res 32, 209, 1996.

65. Moore, M.A., and Phillips, R.E. Biocompatibility and immunologic properties of pericardial tissue stabilized by dye-mediated photooxidation. J Heart Valve Dis 6, 307, 1997.

66. Bengtsson, L.A., Phillips, R., and Haegerstrand, A.N. In vitro endothelialization of photooxidatively stabilized xenogeneic pericardium. Ann Thorac Surg 60(2 Suppl), S365, 1995.

67. Elvin, C.M., Brownlee, A.G., Huson, M.G., Tebb, T.A., Kim, M., Lyons, R.E., Vuocolo, T., Liyou, N.E., Hughes, T.C., Ramshaw, J.A., and Werkmeister, J.A. The development of photochemically crosslinked native fibrinogen as a rapidly formed and mechanically strong surgical tissue sealant. Biomaterials 30, 2059, 2009.

68. Jeon, O., Bouhadir, K.H., Mansour, J.M., and Alsberg, E. Photocrosslinked alginate hydrogels with tunable biodegradation rates and mechanical properties. Biomaterials 30, 2724, 2009.

69. Dong, C.M., Wu, X., Caves, J., Rele, S.S., Thomas, B.S., and Chaikof, E.L. Photomediated crosslinking of C6cinnamate derivatized type I collagen. Biomaterials 26, 4041, 2005.
70. Giannuzzo, M., Corrente, F., Feeney, M., Paoletti, L., Paolicelli, P., Tita, B., Vitali, F., and Casadei, M.A. pH-sensitive hydrogels of dextran: synthesis, characterization and in vivo studies. J Drug Target 16, 649, 2008.

71. Nakayama, Y., and Matsuda, T. Surface fixation of hydrogels. Heparin and glucose oxidase hydrogelated surfaces. ASAIO J 38, M421, 1992.

72. Aldenhoff, Y.B., and Koole, L.H. Studies on a new strategy for surface modification of polymeric biomaterials. J Biomed Mater Res 29, 917, 1995.

73. Vasita, R., Shanmugam, I.K., and Katt, D.S. Improved biomaterials for tissue engineering applications: surface modification of polymers. Curr Top Med Chem 8, 341, 2008.

74. Scheideler, L., Rupp, F., Wendel, H.P., Sathe, S., and Geis-Gerstorfer, J. Photocoupling of fibronectin to titanium surfaces influences keratinocyte adhesion, pellicle formation and thrombogenicity. Dent Mater 23, 469, 2007.

75. Kim, S.W., and Jacobs, H. Design of nonthrombogenic polymer surfaces for blood-contacting medical devices. Blood Purif 14, 357, 1996.

76. Morimoto, N., Watanabe, A., Iwasaki, Y., Akiyoshi, K., and Ishihara, K. Nano-scale surface modification of a segmented polyurethane with a phospholipid polymer. Biomaterials 25, 5353, 2004.

77. Karakeçili, A.G., Satriano, C., Gümüşderelioğlu, M., and Marletta, G. Enhancement of fibroblastic proliferation on chitosan surfaces by immobilized epidermal growth factor. Acta Biomater 4, 989, 2008.

78. Zhu, A.P., Fang, N., Chan-Park, M.B., and Chan, V. Adhesion contact dynamics of 3T3 fibroblasts on poly (lactideco-glycolide acid) surface modified by photochemical immobilization of biomacromolecules. Biomaterials 27, 2566, 2006.

79. Sawhney, A.S., Pathak, C.P., and Hubbell, J.A. Interfacial photopolymerization of poly(ethylene glycol)-based hydrogels upon alginate-poly(l-lysine) microcapsules for enhanced biocompatibility. Biomaterials 14, 1008, 1993.

80. Smeds, K.A., Pfister-Serres, A., Miki, D., Dastgheib, K., Inoue, M., Hatchell, D.L., and Grinstaff, M.W. Photocrosslinkable polysaccharides for in situ hydrogel formation. J Biomed Mater Res 54, 115, 2001.

81. Nguyen, K.T., and West, J.L. Photopolymerizable hydrogels for tissue engineering applications. Biomaterials 23, 4307, 2002.

82. Van Tomme, S.R., Storm, G., and Hennink, W.E. In situ gelling hydrogels for pharmaceutical and biomedical applications. Int J Pharm 355, 1, 2008.

83. Cruise, G.M., Scharp, D.S., and Hubbell, J.A. Characterization of permeability and network structure of interfacially photopolymerized poly(ethylene glycol) diacrylate hydrogels. Biomaterials 19, 1287, 1998.

84. Burdick, J.A., Peterson, A.J., and Anseth, K.S. Conversion and temperature profiles during the photoinitiated polymerization of thick orthopaedic biomaterials. Biomaterials 22, 1779, 2001.

85. Basu, S., and Campagnola, P.J. Properties of crosslinked protein matrices for tissue engineering applications synthesized by multiphoton excitation. J Biomed Mater Res A 71, 359, 2004.

86. Pitts, J.D., Howell, A.R., Taboada, R., Banerjee, I., Wang, J., Goodman, S.L., and Campagnola, P.J. New photoactivators for multiphoton excited three-dimensional submicron 
cross-linking of proteins: bovine serum albumin and type 1 collagen. Photochem Photobiol 76, 135, 2002.

87. Mosesson, M.W., Siebenlist, K.R., and Meh, D.A. The structure and biological features of fibrinogen and fibrin. Ann NY Acad Sci 936, 11, 2001.

88. Jakobsen, R.J., Brown, L.L., Hutson, T.B., Fink, D.J., and Veis, A. Intermolecular interactions in collagen selfassembly as revealed by Fourier transform infrared spectroscopy. Science 220, 1288, 1983.

89. Wallace, D.G., and Rosenblatt, J. Collagen gel systems for sustained delivery and tissue engineering. Adv Drug Deliv Rev 55, 1631, 2003.

90. Chan, B.P., Hui, T.Y., Yeung, C.W., Li, J., Mo, I., and Chan, G.C.F. Self-assembled collagen-human mesenchymal stem cell microspheres for regenerative medicine. Biomaterials 28, 4652, 2007.

91. Chan, B.P., Chan, O.C.M., and So, K.F. Effects of photochemical crosslinking on the microstructure of collagen and a feasibility study on controlled protein release. Acta Biomater 4, 1627, 2008a.

92. Chan, O.C.M., So, K.F., and Chan, B.P. Fabrication of nanofibrous collagen microspheres for protein delivery and effects of photochemical crosslinking on release kinetics. J Control Release 129, 135, 2008 b.

93. Chien, H.W., Chang, T.Y., and Tsai, W.B. Spatial control of cellular adhesion using photo-crosslinked micropatterned polyelectrolyte multilayer films. Biomaterials 30, 2209, 2009.

94. Stefonek, T.J., and Masters, K.S. Immobilized gradients of epidermal growth factor promote accelerated and directed keratinocyte migration. Wound Repair Regen 15, 847, 2007.

95. Miller, D.S., Chirayil, S., Ball, H.L., and Luebke, K.J. Manipulating cell migration and proliferation with a light-activated polypeptide. Chembiochem 10, 577, 2009.

96. Lansche, R.K. Vital staining in normal eyes and in keratoconjunctivitis sicca. Am J Ophthalmol 60, 520, 1965.

97. Penning, L.C., Lagerberg, J.W., VanDierendonck, J.H., Cornelisse, C.J., Dubbelman, T.M., and VanSteveninck, J. The role of DNA damage and inhibition of poly(ADPribosyl)ation in loss of clonogenicity of murine L929 fibroblasts, caused by photodynamically induced oxidative stress. Cancer Res 54, 5561, 1994.

98. Vermonden, T., Fedorovich, N.E., van Geemen, D., Alblas, J., van Nostrum, C.F., Dhert, W.J., and Hennink, W.E. Photopolymerized thermosensitive hydrogels: synthesis, degradation, and cytocompatibility. Biomacromolecules 9, 919, 2008.

99. Sabnis, A., Rahimi, M., Chapman, C., and Nguyen, K.T. Cytocompatibility studies of an in situ photopolymerized thermoresponsive hydrogel nanoparticle system using human aortic smooth muscle cells. J Biomed Mater Res A 91, $52,2009$.

100. Sharma, B., Williams, C.G., Khan, M., Manson, P., and Elisseeff, J.H. In vivo chondrogenesis of mesenchymal stem cells in a photopolymerized hydrogel. Plast Reconstr Surg 119, 112, 2007.

101. Ramaswamy, S., Uluer, M.C., Leen, S., Bajaj, P., Fishbein, K.W., and Spencer, R.G. Noninvasive assessment of glycosaminoglycan production in injectable tissue-engineered cartilage constructs using magnetic resonance imaging. Tissue Eng Part C Methods 14, 243, 2008.

102. Nair, L.S., Bhattacharyya, S., and Laurencin, C.T. Development of novel tissue engineering scaffolds via electrospinning. Expert Opin Biol Ther 4, 659, 2004.

103. Casper, C.L., Yang, W., Farach-Carson, M.C., and Rabolt, J.F. Coating electrospun collagen and gelatin fibers with perlecan domain I for increased growth factor binding. Biomacromolecules 8, 1116, 2007.

104. Li, M., Mondrinos, M.J., Gandhi, M.R., Ko, F.K., Weiss, A.S., and Lelkes, P.I. Electrospun protein fibers as matrices for tissue engineering. Biomaterials 26, 5999, 2005.

105. Zeugolis, D.I., Khew, S.T., Yew, E.S., Ekaputra, A.K., Tong, Y.W., Yung, L.Y., Hutmacher, D.W., Sheppard, C., and Raghunath, M. Electro-spinning of pure collagen nanofibres-just an expensive way to make gelatin? Biomaterials 29, 2293, 2008.

106. Yannas, I.V. Natural materials. In: Ratner, B.D., Hoffman, A.S., Schoen, F.J., and Lemons, J.E., eds. Biomaterials Sciences-An Introduction to Materials in Medicine. San Diego, CA: Academic Press, 1996, pp. 84-93.

107. Liu, T., Choy, A.T.H., Shi, L., Chan, B.P., and Chew, S.Y. Acid-Based Electrospinning of Type I Collagen Nanofibers for Neural Tissue Engineering. Biomaterials Asia 2009, 5-8 April, Hong Kong, PB34.

108. Blättler, T., Huwiler, C., Ochsner, M., Städler, B., Solak, H., Vörös, J., and Grandin, H.M. Nanopatterns with biological functions. J Nanosci Nanotechnol 6, 2237, 2006.

109. Maurya, D.K., Ng, W.Y., Mahabadi, K.A., Liang, Y.N., and Rodríguez, I. Fabrication of lab-on chip platforms by hot embossing and photo patterning. Biotechnol J 2, 1381, 2007.

110. Jang, K., Sato, K., Mawatari, K., Konno, T., Ishihara, K., and Kitamori, T. Surface modification by 2-methacryloyloxyethyl phosphorylcholine coupled to a photolabile linker for cell micropatterning. Biomaterials 30, 1413, 2009.

111. Engler, A.J., Sen, S., Sweeney, H.L., and Discher, D.E. Matrix elasticity directs stem cell lineage specification. Cell 126, 677, 2006.

112. Jay, S.M., and Saltzman, W.M. Shining light on a new class of hydrogels. Nat Biotechnol 27, 43, 2009.

113. Kloxin, A.M., Kasko, A.M., Salinas, C.N., and Anseth, K.S. Photodegradable hydrogels for dynamic tuning of physical and chemical properties. Science 324, 59, 2009.

114. Kloxin, A.M., Benton, J.A., and Anseth, K.S. In situ elasticity modulation with dynamic substrates to direct cell phenotype. Biomaterials 31, 1, 2010.

Address correspondence to: Barbara Pui Chan, Ph.D. Medical Engineering Program Department of Mechanical Engineering

The University of Hong Kong Room 711, Haking Wong Building Pokfulam Road

Hong Kong Special Administrative Region 852

China

E-mail: bpchan@hkucc.hku.hk

Received: December 11, 2009 Accepted: April 14, 2010

Online Publication Date: May 18, 2010 


\section{Appendix I}

\section{Terminology}

Terminologies of photochemistry are used interchangeably and confusingly in different disciplines. This section clarifies some of these confusing terminologies and defines the terminologies used in the current article. Photochemistry is a discipline of chemistry studying the interactions between light and molecules. Photochemical reactions refer to all reactions in photochemistry. Photochemical crosslinking is one type of photochemical reaction and generally describes all photochemical reactions leading to crosslinking of the target molecules. Apart from photochemical crosslinking, photooxidation has also been used frequently in the literature. It constitutes one type of photochemical reaction where oxidation of the target molecules is resulted. Apart from crosslinking and oxidation, the consequence of photochemical reactions could also be po- lymerization if monomers are crosslinked to form polymers or oligomers. In some literature, photoactivated processes have been used to generally describe light-activated processes, including, but are not limited to, those of chemical nature. For example, some photoactivated processes result in thermal effects, called photothermal effects. Photoinitiator and photocrosslinker are used interchangeably with photosensitizer. Function of the former equals that of photosensitizer in initiating a photoactivated process when the target molecules do not absorb photons at a specific wavelength or cannot be activated to produce appropriate photochemical reactions directly by light. The latter reacts itself with the target molecules during photochemical reaction. The difference between photosensitizer and photocrosslinker is that the former may lead to crosslinking of the target molecules, via the indirect mechanism, without consuming itself in the reaction. 